\title{
Wearable Microsensor Array for Multiplexed Heavy Metal Monitoring of Body Fluids
}

Wei Gao, ${ }^{\dagger, \ddagger, \S, \|}$ Hnin Y. Y. Nyein, ${ }^{\dagger, \downarrow, \S, \|}$ Ziba Shahpar, ${ }^{\dagger \dagger}$ Hossain M. Fahad, ${ }^{\dagger \neq}$ Kevin Chen, ${ }^{\dagger, \downarrow, \S}$

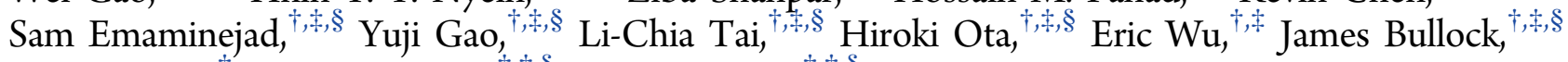
Yuping Zeng, ${ }^{\dagger}$ Der-Hsien Lien, ${ }^{\dagger},, \S$ and Ali Javey ${ }^{*},,+, \S$

${ }^{\dagger}$ Department of Electrical Engineering \& Computer Sciences, and ${ }^{\star}$ Berkeley Sensor and Actuator Center, University of California, Berkeley, California 94720, United States

${ }^{\S}$ Materials Sciences Division, Lawrence Berkeley National Laboratory, Berkeley, California 94720, United States

\section{Supporting Information}

ABSTRACT: A flexible and wearable microsensor array is described for simultaneous multiplexed monitoring of heavy metals in human body fluids. $\mathrm{Zn}, \mathrm{Cd}, \mathrm{Pb}, \mathrm{Cu}$, and $\mathrm{Hg}$ ions are chosen as target analytes for detection via electrochemical square wave anodic stripping voltammetry (SWASV) on $\mathrm{Au}$ and $\mathrm{Bi}$ microelectrodes. The oxidation peaks of these metals are calibrated and compensated by incorporating a skin temperature sensor. High selectivity, repeatability, and flexibility of the sensor arrays are presented. Human sweat and urine samples are collected for heavy metal analysis, and measured results from the microsensors are validated through inductively coupled plasma mass spectrometry (ICP-MS). Real-time on-body evaluation of heavy metal (e.g., zinc and copper)

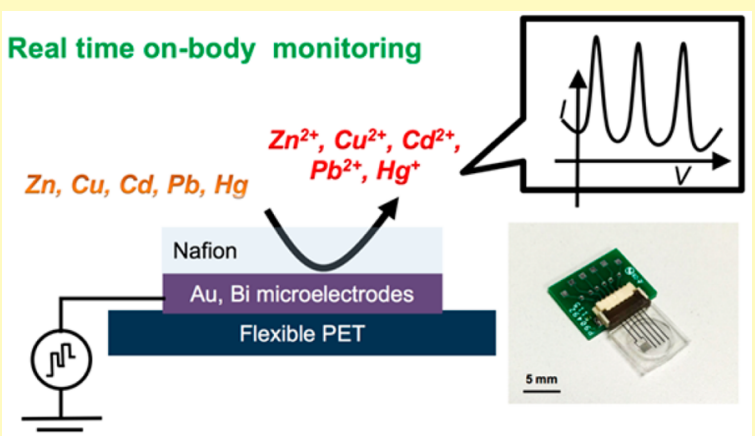
levels in sweat of human subjects by cycling is performed to examine the change in concentrations with time. This platform is anticipated to provide insightful information about an individual's health state such as heavy metal exposure and aid the related clinical investigations.

KEYWORDS: flexible electronics, wearable biosensors, heavy metals monitoring, sweat, multiplexed sensing, temperature compensation

$\mathrm{W}$ earable biosensors can provide insightful information about an individual's health status through real-time monitoring of the physiological status of human subjects. ${ }^{1-12}$ Research advances in this field have led to a variety of physical monitors, which can track an individual's physical activities and reveal vital signs such as blood pressure, heart rate, and skin temperature. $^{3-12}$ To obtain more insightful information regarding health conditions, different groups have developed conformal chemical biosensors which can noninvasively monitor biomarkers in human body fluids including a variety of electrolytes and metabolites. ${ }^{13-22}$ The multiplexed sensing in human sweat samples based on biosensor arrays has been reported recently which allows more accurate and reliable measurements through real-time temperature compensation. ${ }^{23,24}$ However, a wide range of other analytes in body fluids which have close correlation with the health condition of individuals have not been well studied for noninvasive wearable technologies.

Human body fluids are composed of various electrolytes, proteins, metabolites, as well as heavy metals. ${ }^{16}$ A variety of heavy metals can be found in human body fluids (such as blood, sweat, and urine) and are closely related to human health conditions. ${ }^{25-28}$ For instance, $\mathrm{Cu}$ and $\mathrm{Zn}$ are essential trace elements that can have detrimental effects on an individual's health when there is an excess or deficiency. ${ }^{28}$ High copper accumulation in human body can lead to Wilson's disease, ${ }^{29}$ heart and kidney failure, liver damage, brain disease and disorder, and even death in extreme cases, whereas low levels of copper can cause anemia and osteoporosis. A lethal form of diarrhea and pneumonia can occur when a body has low zinc concentrations, whereas high levels of zinc can be toxic enough to cause liver damage, and even decrease cardiac functionality and pancreatic enzyme count in cases of prolonged exposure. $^{28}$ Additionally, cadmium, lead, and mercury exhibit toxic effects on human body systems including the nervous, immunological, and cardiovascular systems. ${ }^{26,27}$ High levels of cadmium exposure can lead to fatal respiratory tract, liver, and kidney problems. On the other hand, lead poisoning can slow down growth and cause other developmental delay as well as irritability, increased violent behavior, learning difficulties, fatigue, loss of appetite, and hearing loss for children and cause memory loss, infertility, high blood pressure, and decline in mental functioning for adults. ${ }^{26,27}$ Lastly, mercury poisoning leads to many diseases such as Hunter-

Received: April 26, 2016

Accepted: May 9, 2016

Published: May 9, 2016 

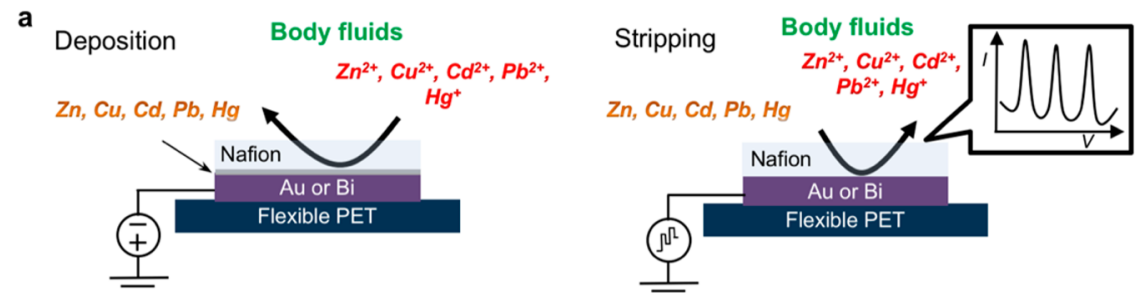

b

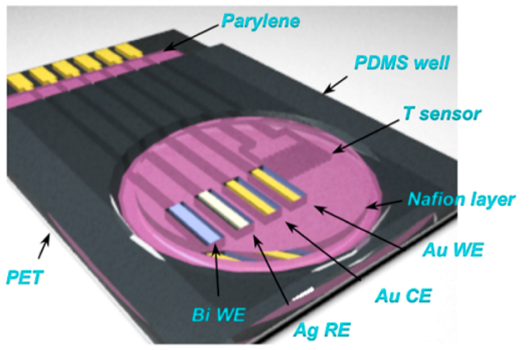

c

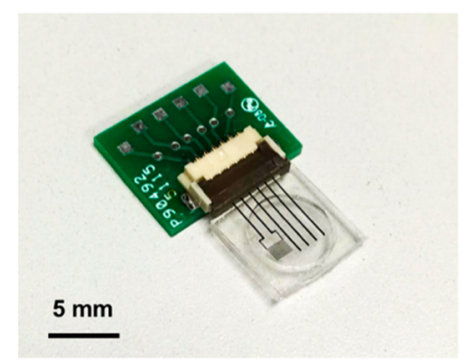

Figure 1. Flexible microsensor arrays for multiplexed heavy metals analysis. (a) Schematic showing the concept of deposition and stripping on microelectrodes. (b) Schematic showing the composition of the microsensor array. (c) Optical image of a flexible sensor array interfacing with a flexible printed circuit connector.

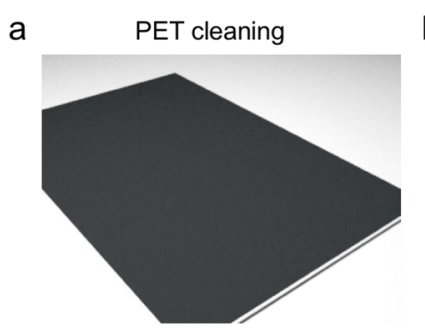

d

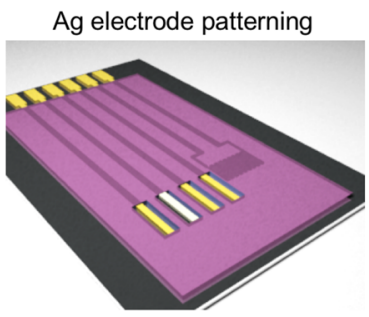

g

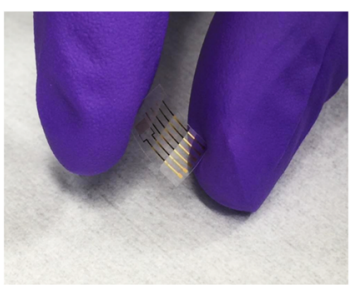

b

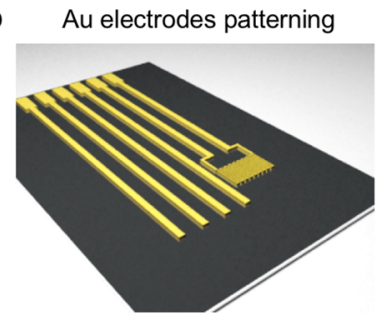

e

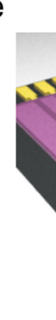

C Parylene patterning for insulation

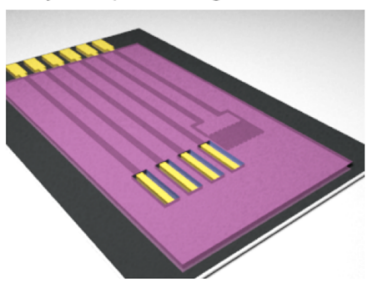

f

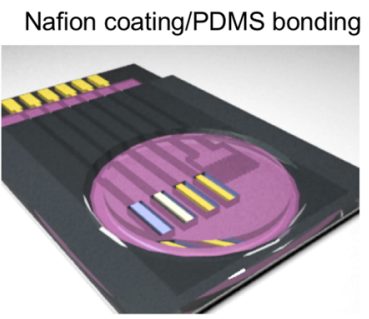

$\mathrm{h}$
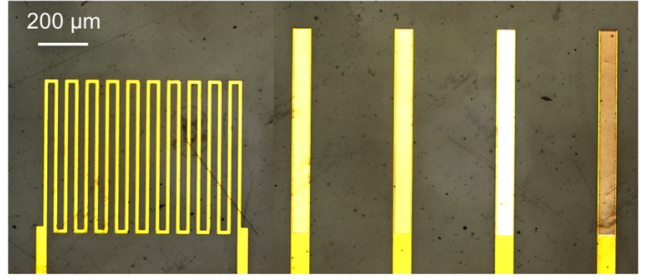

Figure 2. Fabrication process of flexible microsensor arrays. (a) Cleaning of PET substrate using acetone, isopropanol, and $\mathrm{O}_{2}$ plasma etching. (b) Patterning of $\mathrm{Cr} / \mathrm{Au}$ electrodes via photolithography, e-beam evaporation, and lift-off in acetone. (c) Parylene insulating layer deposition, photolithography, and $\mathrm{O}_{2}$ plasma etching of parylene in the electrode areas. (d) E-beam deposition of Ag layer followed by lift-off in acetone. (e) Photolithography and e-beam deposition of Bi layer followed by lift-off in acetone. (f) Nafion coating and PDMS bonding. (g) An optical image of a flexible electrode array. (h) Microscopic image of a multiplexed microsensor array.

Russell syndrome, Minamata disease, and acrodynia, to name a few. ${ }^{26,27}$ Therefore, determining one's exposure to such heavy metals can offer important insights into a person's health. Human sweat and urine are known to be the most important sources for detoxification of heavy metals; ${ }^{26}$ therefore, examination of sweat and urine heavy metals can assist toxicological and therapeutic studies.

Detection of heavy metals in body fluids is challenging due to their extremely low concentrations (on the order of $\mu \mathrm{g} / \mathrm{L}$ ).
Conventional heavy metals analysis procedures including atomic absorption spectroscopy (AAS) or inductively coupled plasma mass spectrometry (ICP-MS) rely on bulky and expensive analytical instruments. ${ }^{30,31}$ The effective preconcentration/deposition step and advanced electrochemical measurements of the accumulated analytes make anodic stripping analysis the most sensitive and effective electroanalytical technique. $^{32}$ The stripping-voltammetric measurements of trace metals in sweat have been reported using collected 

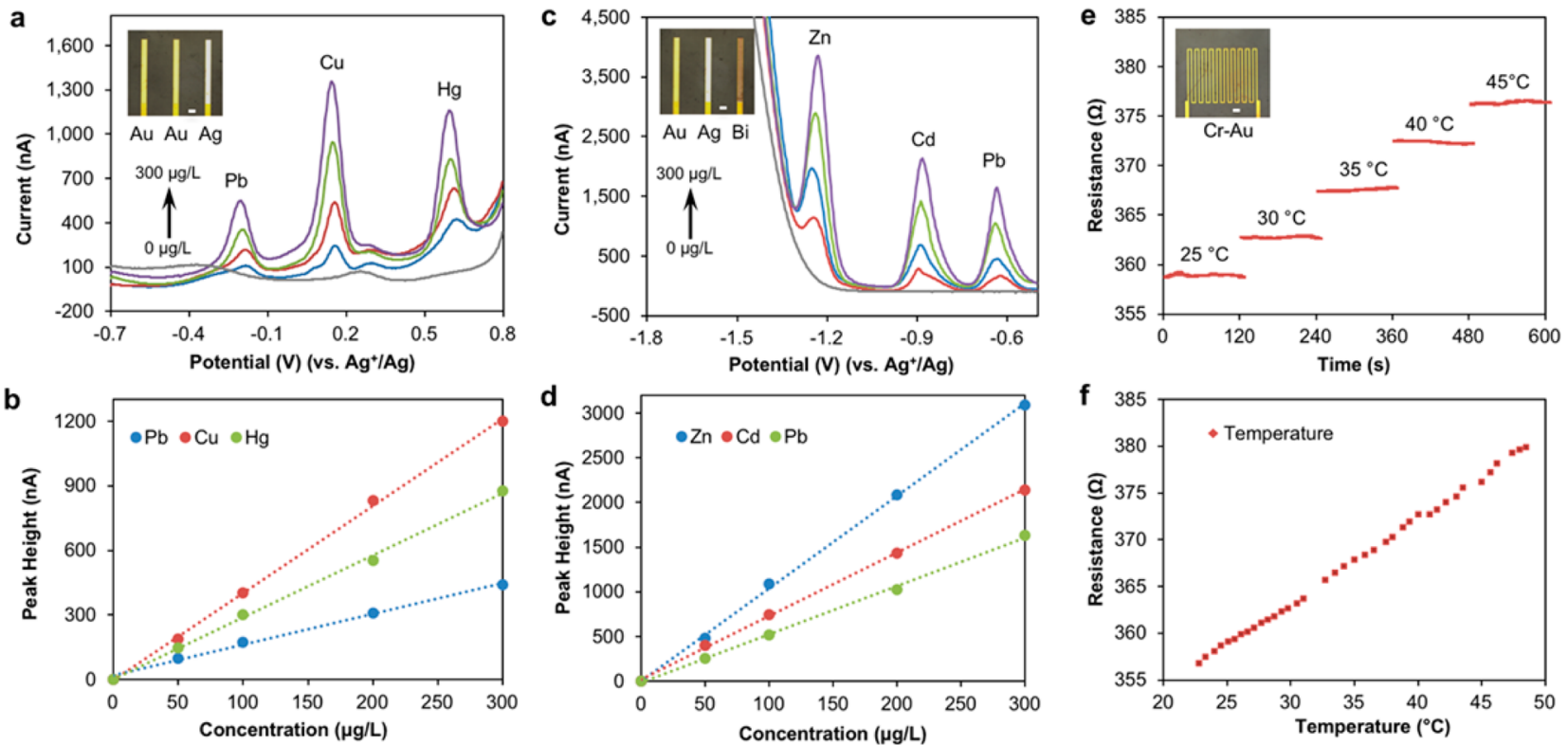

Figure 3. Characterization of $\mathrm{Au}$ and $\mathrm{Bi}$ microelectrodes for trace metal detection. $(\mathrm{a}, \mathrm{b})$ Stripping voltammograms (a) and calibration curves (b) of $\mathrm{Pb}, \mathrm{Cu}$, and $\mathrm{Hg}(0,50,100,200,300 \mu \mathrm{g} / \mathrm{L})$ using a Au working microelectrode, a Ag reference microelectrode, and a Au auxiliary microelectrode. Deposition at $-0.7 \mathrm{~V}$ for $120 \mathrm{~s}$; stripping up to $0.8 \mathrm{~V}$ using a frequency of $60 \mathrm{~Hz}$, an amplitude of $40 \mathrm{mV}$, and a potential step of $4 \mathrm{mV}$. (c,d) Stripping voltammograms (c) and calibration curves (d) of $\mathrm{Zn}, \mathrm{Cd}$, and $\mathrm{Pb}(0,50,100,200,300 \mu \mathrm{g} / \mathrm{L})$ using a Bi working microelectrode, a $\mathrm{Ag}$ reference microelectrode, and a Au auxiliary microelectrode. Deposition at $-1.5 \mathrm{~V}$ for $180 \mathrm{~s}$, stripping up to $-0.5 \mathrm{~V}$ using a frequency of $60 \mathrm{~Hz}$, an amplitude of $40 \mathrm{mV}$, and a potential step of $4 \mathrm{mV}$. SWASV was performed in $50 \mu \mathrm{L}$ of $0.01 \mathrm{M}$ acetate buffer (pH 4.6) containing $50 \mathrm{mM} \mathrm{NaCl}$ with addition of the respective heavy metal standard solution (for a and c). (e,f) Resistance response (e) and calibration curve (f) of the temperature sensor to temperature changes $\left(20-50{ }^{\circ} \mathrm{C}\right)$ in $0.01 \mathrm{M}$ acetate buffer $(\mathrm{pH} 4.6)$ containing $50 \mathrm{mM} \mathrm{NaCl}$. Insets in (a), (c), and (e) show the microscopic images of each microsensor (scale bars, $100 \mu \mathrm{m}$ ).

sweat samples. ${ }^{33-36}$ Such use of collected sweat may be subject to inaccuracy due to sample contamination and sweat evaporation. In addition, it cannot yield real-time information on dynamic events. Recently, on-body detection of zinc in sweat has also been reported using printed epidermal tattoos. ${ }^{37}$ Given the importance or toxicity of a variety of heavy metals to the individual's health states, it is very attractive to perform simultaneous multiplexed screening of heavy metals in sweat and do proper signal calibrations to ensure accurate measurements.

In this paper, we demonstrate a flexible multiplexed trace metals monitoring device to extract useful information on heavy metal levels in body fluids such as sweat and urine. It can also be used as a wearable device for real-time monitoring of the heavy metals in human sweat. A microsensor array is utilized to simultaneously and selectively measure multiple heavy metals including $\mathrm{Zn}, \mathrm{Cd}, \mathrm{Pb}, \mathrm{Cu}$, and $\mathrm{Hg}$ through square wave anodic stripping voltammetry (SWASV), as well as the skin temperature to calibrate heavy metal sensors' readings in real-time (Figure 1a). The microsensor array consists of four microelectrodes: biocompatible gold and bismuth working electrodes (WE), a silver reference electrode (RE), and a gold counter/ auxiliary electrode (CE) (Figure $1 \mathrm{~b}$ ). In addition, a resistancebased skin temperature sensor based on evaporated $\mathrm{Cr} / \mathrm{Au}$ microlines is integrated into the system to compensate the sensors' readings since temperature has a significant influence on the electrochemical processes. Furthermore, on-body measurements of sweat trace metals during exercise are performed by implementing the integrated sensors directly on human skin. Such real-time assessment of heavy metals in sweat can give early warnings of heavy metal exposure.
The choice of the working electrode is crucial for successful stripping analysis. The ideal material for working electrode should offer an effective preconcentration, a favorable redox reaction of the target metal, reproducible and renewable surface, and a low background current over a wide potential range. $^{32}$ Although mercury has been the most explored electrode for many stripping applications, it is not desired for wearable biosensors given its toxicity and volatility. ${ }^{38}$ In contrast, the attractive stripping voltammetric performance and biocompatibility of the bismuth and gold electrodes can serve as the ideal candidate for developing wearable biosensors for heavy metals analysis. 38,39

\section{RESULTS AND DISCUSSION}

The microsensors arrays are fabricated on a flexible polyethylene terephthalate (PET) substrate through a procedure involving multiple steps of photolithography, evaporation $(\mathrm{Cr} /$ $\mathrm{Au}, \mathrm{Ag}, \mathrm{Bi}$ ), and lift-off as demonstrated in Figure 2. A $500 \mathrm{~nm}$ layer of parylene $\mathrm{C}$ is chosen as an insulation layer to ensure reliable measurement by preventing electrical contact of the conducting metal lines with body fluids and skin. Photolithography and $\mathrm{O}_{2}$ plasma etching are used to define the electrode area $(100 \mu \mathrm{m} \times 1200 \mu \mathrm{m})$. After patterning the $\mathrm{Ag}$ reference, $\mathrm{Bi}$ and Au working electrodes, a thin Nafion coating is used as an antifouling layer to minimize biofouling of surfaceactive macromolecules such as proteins. ${ }^{40}$ A polydimethylsiloxane (PDMS) well (6 mm diameter and $1 \mathrm{~mm}$ thickness) was also bonded on top of the sensor array by soft lithography and $\mathrm{O}_{2}$ plasma etching. This ensures sweat accumulation (20-30 $\mu \mathrm{L}$ ) such that a stable and reliable stripping analysis can be done. The microelectrodes array is then connected to a 

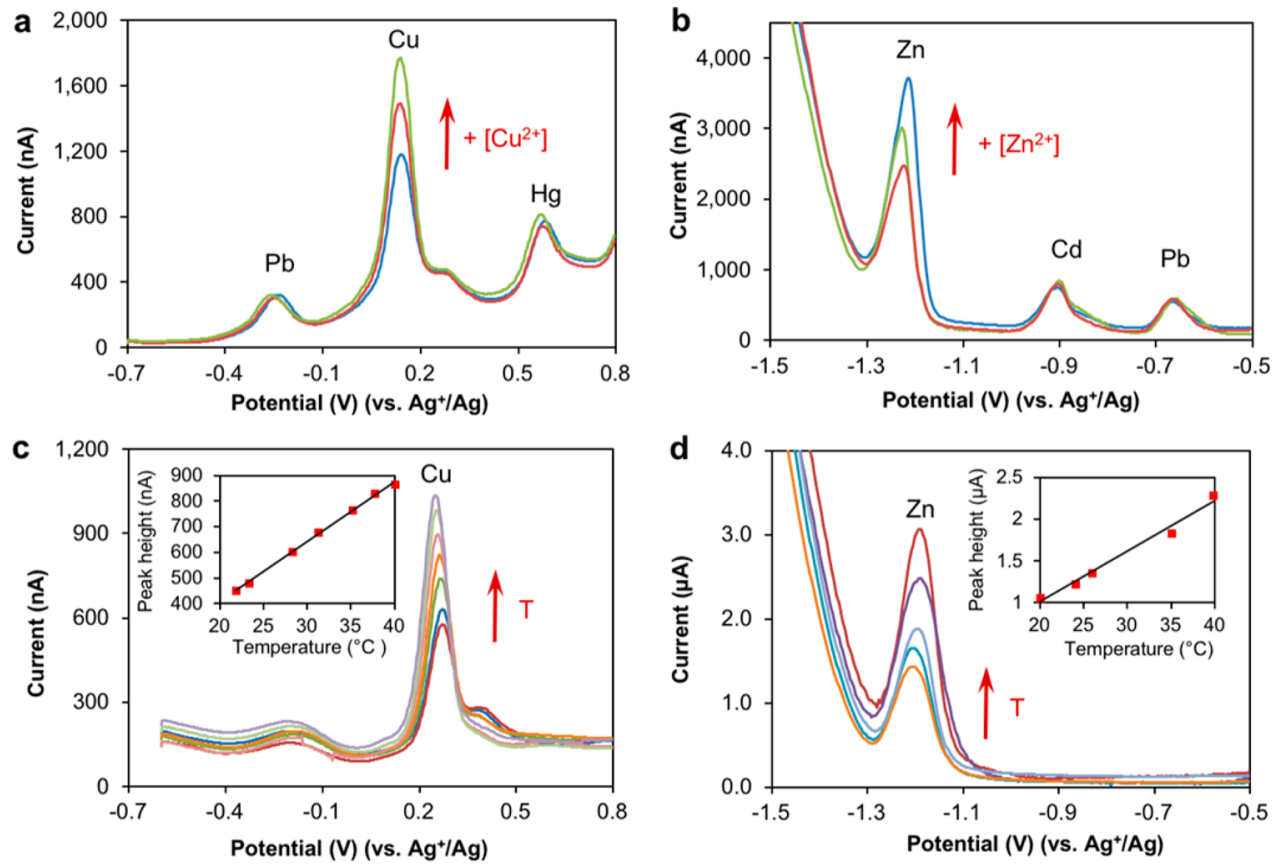

Figure 4. Interference study and temperature compensation. (a) Interference study on a $\mathrm{Au}$ working electrode by varying $\mathrm{Cu}$ concentrations. Stripping conditions, same as Figure 3a. (b) Interference study on a Bi working electrode by varying Zn concentrations. Stripping conditions, same as Figure 3c. (c) Stripping voltammograms for $\mathrm{Cu}$ using a Au microelectrode at physiological skin temperature range $\left(20-40{ }^{\circ} \mathrm{C}\right)$ in $0.01 \mathrm{M}$ acetate buffer ( $\mathrm{pH}$ 4.6) containing $50 \mathrm{mM} \mathrm{NaCl}$ and $100 \mu \mathrm{g} / \mathrm{L} \mathrm{Cu}$. Stripping conditions, same as Figure 3a. (d) Stripping voltammograms for $\mathrm{Zn}$ using a Bi microelectrode at physiological skin temperature range $\left(20-40^{\circ} \mathrm{C}\right.$ ) in $0.01 \mathrm{M}$ acetate buffer $(\mathrm{pH} 4.6)$ containing $50 \mathrm{mM} \mathrm{NaCl}$ and $100 \mu \mathrm{g} / \mathrm{L} \mathrm{Zn}$. Stripping conditions, same as Figure $3 \mathrm{c}$. Insets in (c) and (d) show the corresponding temperature calibration plots of the sensors.

potentiostat through an interface consisting of a flexible printed circuit (FPC) connector (Figure 1c).

As aforementioned, $\mathrm{Au}$ microelectrodes offer excellent biocompatibility and a wide operational potential window owing to their high stability. Au is an ideal electrode material for $\mathrm{Pb}, \mathrm{Cu}$, and $\mathrm{Hg}$ stripping. In order to investigate the relationship between the concentration of heavy metals and the response of SWASV, the voltammograms are recorded using a $0.01 \mathrm{M}$ acetate buffer solution ( $\mathrm{pH} 4.6)$ containing $50 \mathrm{mM}$ $\mathrm{NaCl}$ (to mimic human sweat) with an addition of $50-100 \mu \mathrm{g} /$ $\mathrm{L}$ heavy metals after every trial. As illustrated in Figure 3a, three distinct peaks near $-0.2,0.2$, and $0.6 \mathrm{~V}$ which correspond to oxidation of $\mathrm{Pb}, \mathrm{Cu}$, and $\mathrm{Hg}$, respectively, are observed for a $\mathrm{Au}$ microelectrode. A linear relationship between the peak height (current amplitude measured from the baseline as illustrated in Figure S1) and analyte concentration with sensitivities of 1.4, 4.1, and $2.9 \mathrm{nA} \cdot \mathrm{L} / \mu \mathrm{g}$ for $\mathrm{Pb}, \mathrm{Cu}$, and $\mathrm{Hg}$, respectively, is demonstrated in Figure $3 \mathrm{~b}$. It should be noted that no distinct oxidation peak of $\mathrm{Cd}$ was observed in our experiments using $\mathrm{Au}$ microelectrodes, consistent with previous reports. ${ }^{39}$ In addition, although it is also possible to obtain the oxidation peak for $\mathrm{Zn}$ using $\mathrm{Au}$ microelectrodes, $\mathrm{Zn}$ stripping results in strong hydrogen evolution because $\mathrm{Zn}$ deposits and strips at a very negative potential (close to the hydrogen evolution potential) compared to other trace metals. ${ }^{41}$ On the other hand, $\mathrm{Bi}$ electrodes offer great biocompatibility with high sensitivity, and low sensitivity to dissolved oxygen. ${ }^{38}$ Despite these advantages, $\mathrm{Bi}$ electrodes are not suitable for stripping $\mathrm{Cu}$ and $\mathrm{Hg}$ due to its relatively lower oxidation potential $(\sim-0.3 \mathrm{~V})$. Hence, a $\mathrm{Bi}$ microelectrode is only utilized for $\mathrm{Cd}, \mathrm{Pb}$, and $\mathrm{Zn}$ detection. Figure $3 \mathrm{c}$ shows three distinct oxidation peaks for $\mathrm{Zn}, \mathrm{Cd}$, and $\mathrm{Pb}$ near $-1.2,-0.9$, and $-0.6 \mathrm{~V}$, respectively, from a $\mathrm{Bi}$ microelectrode. The corresponding sensitivities for $\mathrm{Zn}, \mathrm{Cd}$, and
$\mathrm{Pb}$ are 10.4, 7.1, and $5.4 \mathrm{nA} \cdot \mathrm{L} / \mu \mathrm{g}$, respectively (Figure $3 \mathrm{~d}$ ). Note that high current at a very negative potential before the zinc peak is observed due to the hydrogen evolution. Figure $3 \mathrm{e}$ and $3 \mathrm{f}$ displays the linear response of a temperature sensor in physiological skin temperature range with a sensitivity of $\sim 0.24 \% /{ }^{\circ} \mathrm{C}$ (normalized to the resistance at $20{ }^{\circ} \mathrm{C}$ ).

The selectivity of the $\mathrm{Bi}$ and $\mathrm{Au}$ based microsensors are of great importance for the analysis in biofluids. Given the relatively high concentration of sweat $\mathrm{Cu}$ and $\mathrm{Zn}$ (on the order of hundreds $\mu \mathrm{g} / \mathrm{L}$ ), an interference study on $\mathrm{Au}$ and $\mathrm{Bi}$ based microsensors is implemented by varying $\mathrm{Cu}$ and $\mathrm{Zn}$ concentrations, respectively. As illustrated in Figure $4 \mathrm{a}$, while the $\mathrm{Cu}$ concentration increases from 200 to 250 and $300 \mu \mathrm{g} / \mathrm{L}$, the $\mathrm{Cu}$ current peak significantly increases while the current peaks of $\mathrm{Pb}$ and $\mathrm{Hg}$ (with a significantly lower concentration of $100 \mu \mathrm{g} / \mathrm{L}$ ) remain unchanged. Similarly, while the $\mathrm{Zn}$ concentration is raised from 200 to 250 and $300 \mu \mathrm{g} / \mathrm{L}$, the oxidation peak of $\mathrm{Zn}$ increases linearly with its concentration while there are no clear interferences on the peaks of $\mathrm{Cd}$ and $\mathrm{Pb}$ (with a concentration of $100 \mu \mathrm{g} / \mathrm{L}$ ) (Figure $4 \mathrm{~b}$ ). Likewise, when varying concentrations of $\mathrm{Cd}, \mathrm{Pb}$, and $\mathrm{Hg}$, no obvious interferences for the measurements of the other metals were observed on the $\mathrm{Bi}$ and $\mathrm{Au}$ microelectrodes. Such high selectivity of stripping analysis among the target heavy metals is crucial for the on-body test given the high complexity of human body fluids.

Another important aspect needed to be considered is the influence of temperature on the responses of biosensors. It has been reported that skin temperature and environmental temperature can have direct influence on metabolite sensors; hence, temperature compensation is essential to ensure accurate readings of the sensors. ${ }^{23}$ To this end, SWASV responses of the microsensors are investigated by gradually 

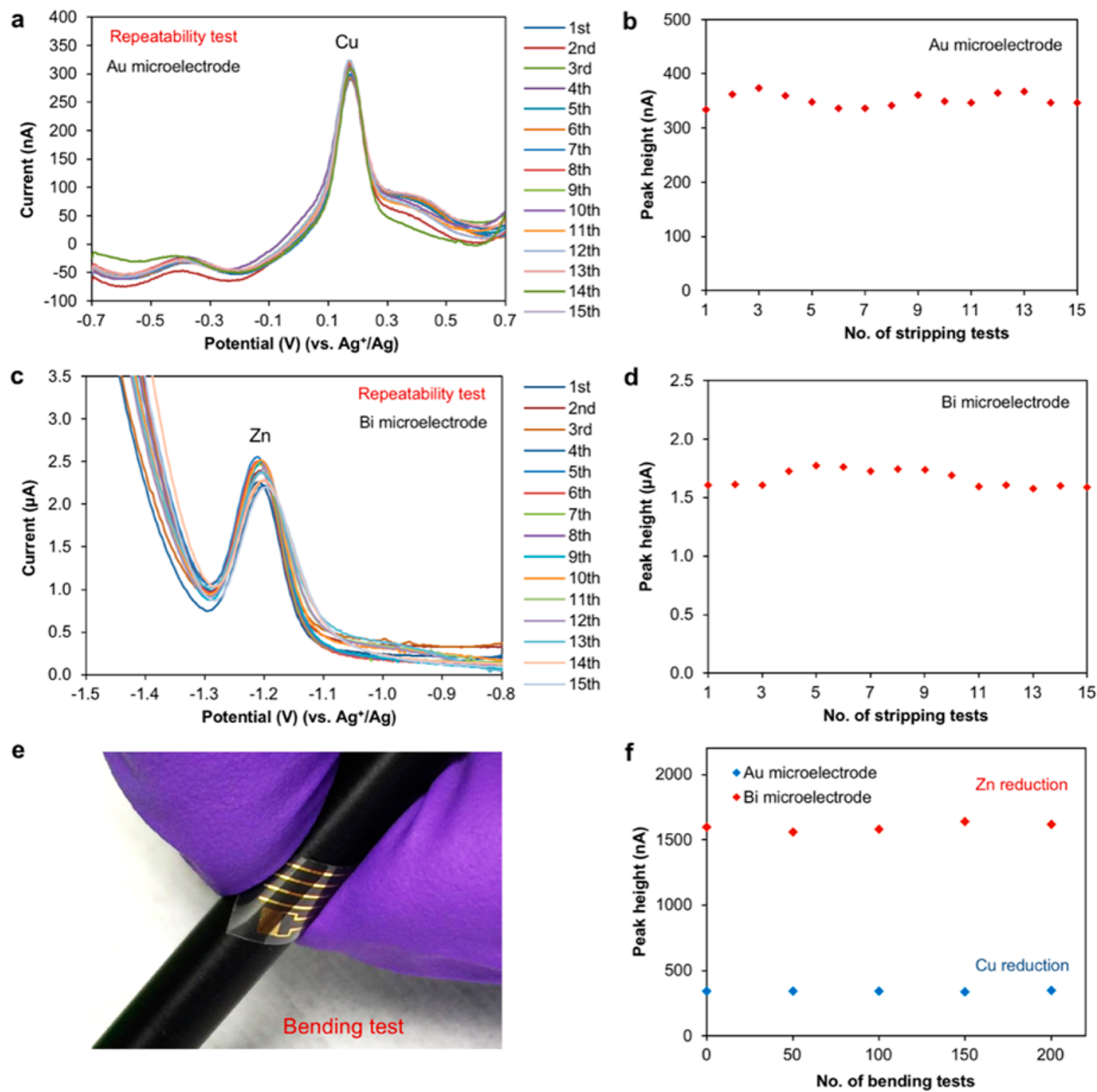

Figure 5. Stability and repeatability of the microsensor arrays. (a,b) Stripping voltammograms (a) and corresponding peak height (b) continuously recorded with a gold microelectrode for 15 times in $0.01 \mathrm{M}$ acetate buffer $(\mathrm{pH} 4.6)$ containing $50 \mathrm{mM} \mathrm{NaCl}$ and $150 \mu \mathrm{g} / \mathrm{L} \mathrm{Cu}$. Deposition at $-0.7 \mathrm{~V}$ for $15 \mathrm{~s}$; other stripping conditions, same as Figure 3a. (c,d) Stripping voltammograms (c) and corresponding peak height (b) continuously recorded with a bismuth microelectrode for 15 times in $0.01 \mathrm{M}$ acetate buffer ( $\mathrm{pH} 4.6)$ containing $50 \mathrm{mM} \mathrm{NaCl}$ and $150 \mu \mathrm{g} / \mathrm{L} \mathrm{Zn}$. Stripping conditions, same as Figure 3c. (e) Image of mechanical bending of a microsensor array (radii of curvature: $3.2 \mathrm{~mm}$ ). (f) Peak height of the corresponding stripping results for $150 \mu \mathrm{g} / \mathrm{L} \mathrm{Cu}$ and $150 \mu \mathrm{g} / \mathrm{L} \mathrm{Zn}$ on $\mathrm{Au}$ and Bi based microsensors, respectively. Conditions, same as Figure 5a and b.

increasing the temperature of the solution containing $\mathrm{Cu}(\mathrm{II})$ and $\mathrm{Zn}(\mathrm{II})$ from 20 to $40{ }^{\circ} \mathrm{C}$. As shown in Figure $4 \mathrm{c}$ and $\mathrm{d}$, responses of both $\mathrm{Au}$ and $\mathrm{Bi}$ electrodes increase almost linearly with increasing solution temperature over the range with a slope of $5.5 \% /{ }^{\circ} \mathrm{C}$ and $6 \% /{ }^{\circ} \mathrm{C}$, respectively, relative to the peak height at $20^{\circ} \mathrm{C}$. The increase in the sensors' responses reflects the elevated mass transport and electrochemical deposition and stripping kinetics. The integration of a temperature sensor into the microsensor array allows real-time temperature compensation to ensure an accurate and a reliable heavy metal detection.

The repeatability of $\mathrm{Au}$ and $\mathrm{Bi}$ based microsensors for stripping analysis of $\mathrm{Cu}$ and $\mathrm{Zn}$ was examined by recording the stripping voltammograms under the same condition mentioned above in a solution containing $150 \mu \mathrm{g} / \mathrm{L} \mathrm{Cu}$ and $\mathrm{Zn}$, respectively. Figure $5 \mathrm{a}$ and $\mathrm{b}$ shows 15 continuous stripping voltammograms and corresponding peak height for $\mathrm{Cu}$ detection using the same Au microelectrode. The relative standard deviation (RSD) of the peak measurements is 3.6\%. Similarly, Figure $5 \mathrm{c}$ and $\mathrm{d}$ illustrates the stripping voltammo- grams and corresponding peak height for $\mathrm{Zn}$ detection using a $\mathrm{Bi}$ microelectrode with a $4.4 \%$ RSD for the peak height measurements. It should be noted that the Au-based sensors remain stable even after 100 times measurements while the performance of Bi-based sensors gradually decreases after 15 times test due to the consumption of Bi film. In addition, the reproducibility of different microsensor arrays for heavy metal analysis was examined. As demonstrated in Figure S2, the corresponding RSDs for $\mathrm{Cu}$ and $\mathrm{Zn}$ analysis using eight different microsensor arrays are $4.6 \%$ and $3.9 \%$, respectively. Unlike the most common type of electroplated thick Bi film electrode, the Bi microelectrode displays excellent repeatability due to the high uniformity of the evaporated Bi film. It has been reported that the use of micro/nanoelectrodes can greatly enhance the mass transport rate due to small size. ${ }^{42}$ Additionally, the magnetic stirring commonly used for SWASV of regular macroscale electrodes to obtain repeatable and reliable data is avoided in our study. This represents a 
major advantage for the use of microelectrodes on wearable sensing devices.

The wearable microsensor array must be able to withstand mechanical deformation during vigorous physical exercise. The flexibility was investigated by monitoring the peak heights of stripping performance of the sensor array after mechanical bending (radii of curvature is $3.2 \mathrm{~mm}$ ) (Figure 5e). As demonstrated in Figure 5f, no obvious variations (relative standard deviations are $1 \%$ and $1.9 \%$ for $\mathrm{Cu}$ and $\mathrm{Zn}$ detection, respectively) are observed for the stripping data even after 200 times bending tests. This indicates that the flexible microsensor array is robust enough for on-body test to endure the excess deformation during physical exercise.

A stable and a reliable performance of biosensors in biofluids is necessary for practical usage. To demonstrate such capability of the microsensor array (not only for on-body real-time monitoring but also for off-body analysis of different biofluids), sweat and urine samples are collected from volunteer subjects for off-body measurements. The physiological levels of all heavy metals in human sweat and urine are relatively low $(<1 \mathrm{mg} / \mathrm{L})$. Specifically, human sweat contains $100-1000 \mu \mathrm{g} / \mathrm{L}$ of $\mathrm{Zn}$ and $\mathrm{Cu}$ while the concentrations of $\mathrm{Pb}, \mathrm{Cd}$, and $\mathrm{Hg}$ usually fall below $100 \mu \mathrm{g} / \mathrm{L}^{25-28}$ Because of the relatively high concentrations of free $\mathrm{Cu}$ and $\mathrm{Zn}$ ions, off-body measurements showed visible oxidation peaks in sweat and urine samples of all the subjects. For $\mathrm{Cu}$ stripping, $15 \mathrm{~s}$ deposition time was used on the $\mathrm{Au}$ microelectrodes to minimize peak distortion and electrode fouling. ${ }^{29}$ In addition, the permselective/protective Nafion coating is found to be essential to address the challenge of biofouling due to the surface-active compounds in complex human biofluids. ${ }^{40}$ It helps to enhance oxidation peaks of targeted trace metals and allows direct detection in human sweat and urine samples. $\mathrm{Cu}$ and $\mathrm{Zn}$ levels in sweat (Figure S3a and b) and urine samples (Figure S3c and d) were determined by manual addition of target metal and back-calculating sweat concentrations as detailed in Experimental Section. Such a standard calibration method could minimize the potential influence of $\mathrm{Cu}-\mathrm{Zn}$ intermetallic compounds formed on $\mathrm{Bi}$ electrodes (due to the high $\mathrm{Cu}$ levels in biofluids). ${ }^{19}$ Sweat samples were collected from subjects during a constant load indoor cycling exercise, while human urine samples were obtained from volunteer subjects. The measured concentrations of $\mathrm{Cu}$ and $\mathrm{Zn}$ in sweat and urine are consistent with earlier findings reported in the literature. ${ }^{30,33}$ Concentrations of $\mathrm{Cu}$ and $\mathrm{Zn}$ in biofluids were also validated with inductively coupled plasma mass spectrometry (ICP-MS). Table 1 illustrates the comparison between the measured concentrations of $\mathrm{Cu}$ and $\mathrm{Zn}$ in sweat and urine samples by using the microsensor array

Table 1. Comparison of the Measurement Results for $\mathrm{Cu}$ and $\mathrm{Zn}$ Content in Collected Human Sweat and Urine Samples from a Volunteer Subject Using the Microsensors and ICP-MS

\begin{tabular}{|c|c|c|}
\hline sample & $\begin{array}{l}\text { measurement results from the } \\
\text { microsensor arrays }(\mu \mathrm{g} / \mathrm{L})\end{array}$ & $\begin{array}{l}\text { measurement results from } \\
\text { ICP-MS }(\mu \mathrm{g} / \mathrm{L})\end{array}$ \\
\hline $\begin{array}{c}\text { sweat } \\
\mathrm{Cu}\end{array}$ & 249 & 267 \\
\hline $\begin{array}{c}\text { sweat } \\
\mathrm{Zn}\end{array}$ & 274 & 290 \\
\hline $\begin{array}{r}\text { urine } \\
\mathrm{Cu}\end{array}$ & 571 & 601 \\
\hline $\begin{array}{c}\text { urine } \\
\mathrm{Zn}\end{array}$ & 624 & 634 \\
\hline
\end{tabular}

and by the ICP-MS method. No significant difference was observed between these two methods. This confirms that the microsensor array can be used for accurate measurement of heavy metals in sweat and urine. Although no obvious oxidation peaks of $\mathrm{Pb}, \mathrm{Cd}$, or $\mathrm{Hg}$ are observed due to their low concentration in sweat and urine of normal subjects, it is possible to detect them using the microelectrodes in those who are subjected to heavy exposure. It has been reported that $\mathrm{Pb}$ and $\mathrm{Cd}$ can reach $200-300 \mu \mathrm{g} / \mathrm{L}$ in sweat for the subjects undergoing heavy exposure. ${ }^{26,43}$ Figure 6 depicts the sensitivity of microsensors when heavy metals reach toxic levels in raw sweat (with the addition of $200 \mu \mathrm{g} / \mathrm{L}$ target analytes including $\mathrm{Zn}, \mathrm{Pb}$, and $\mathrm{Cd}$ ).

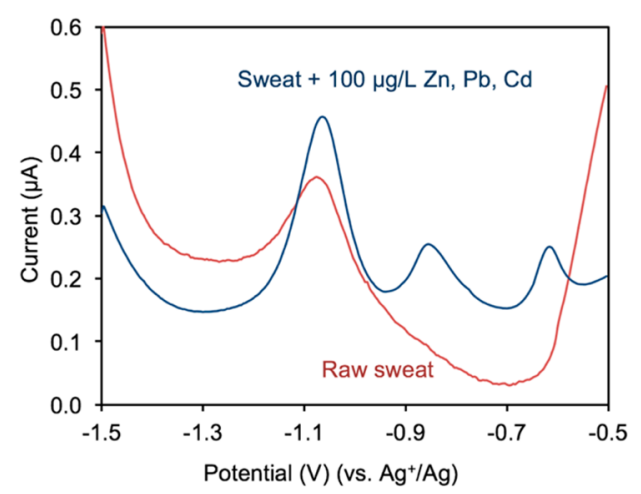

Figure 6. Multiplexed heavy metal analysis in collected human sweat. Stripping voltammograms for detection of $\mathrm{Zn}, \mathrm{Cd}$, and $\mathrm{Pb}$ in a raw human sweat sample (collected from a subject during indoor cycling exercise) and in the same sweat sample with a standard addition of 200 $\mu \mathrm{g} / \mathrm{L}$ of $\mathrm{Zn}, \mathrm{Cd}$, and $\mathrm{Pb}$. Conditions, same as Figure $3 \mathrm{c}$.

On-body heavy metals monitoring was performed during a constant-load exercise on a cycle ergometer. The protocol involved a $5 \mathrm{~min}$ ramp-up, $30 \mathrm{~min}$ cycling at $150 \mathrm{~W}$, and a 5 min cool-down. The microsensor arrays were packaged in a wristband (Figure 7a) which could be comfortably worn by the subject. During the exercise, the skin temperature, sweat $\mathrm{Cu}$, and sweat $\mathrm{Zn}$ were monitored by using an electrochemical potentiostat. Figure $7 \mathrm{~b}$ and $\mathrm{c}$ shows the calibrated stripping voltammograms for heavy metal detection recorded by the microsensor array at different time during the exercise of a volunteer subject. The current readings were calibrated according to the real-time temperature information (stabilized at $\sim 34{ }^{\circ} \mathrm{C}$ during the measurement period). It can be clearly seen that the initial concentrations of sweat copper and sweat zinc are high. As exercise continues, $\mathrm{Cu}$ and $\mathrm{Zn}$ concentrations decrease and gradually reach stable levels during the rest of the exercise. This general trend is also consistent with the ICP-MS data obtained from collected sweat samples in every $5 \mathrm{~min}$ period (Figure $7 \mathrm{~d}$ ). The slightly higher value from the on-body measurement is likely due to enhanced diffusion in the sweat sample during the deposition period caused by the subject's vigorous motion.

\section{CONCLUSIONS}

In conclusion, we have developed a wearable and flexible microsensor array that can perform simultaneous and selective detection of multiple heavy metals (e.g., $\mathrm{Zn}, \mathrm{Cd}, \mathrm{Pb}, \mathrm{Cu}$, and $\mathrm{Hg}$ ) noninvasively. The flexible microsensor arrays display very good repeatability and stability for heavy metal analysis. A temperature sensor is utilized for real-time compensation of the 

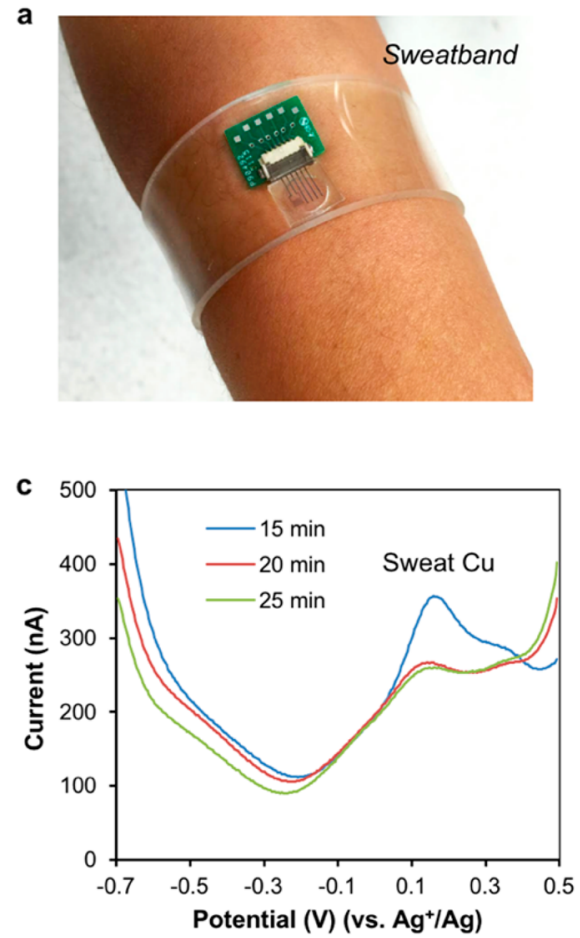
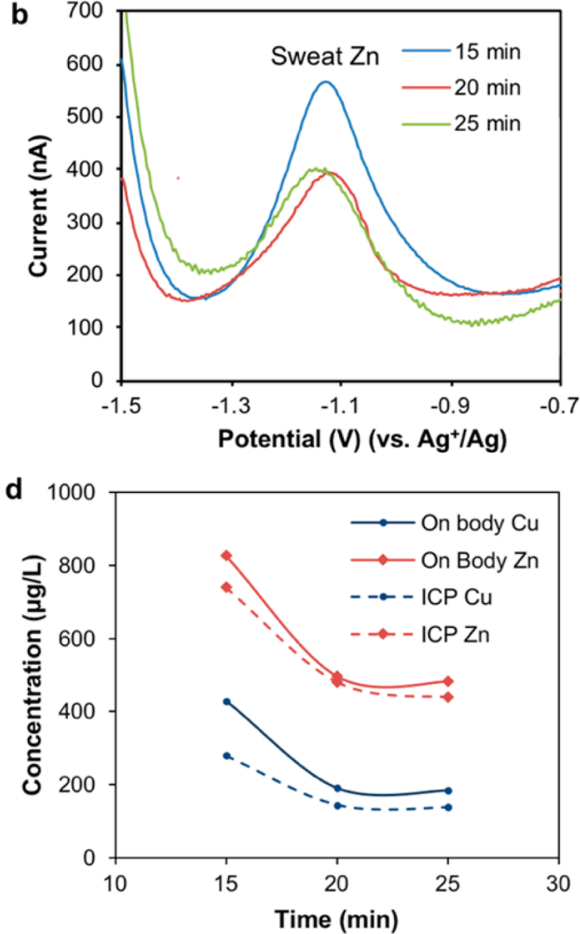

Figure 7. On body multiplexed trace metal detection using a microsensor array during a constant load (150 W) indoor cycling exercise. (a) Image of a microsensor array packaged in a transparent wristband. (b) On-body real time $\mathrm{Zn}$ analysis using a Bi based microsensor at different cycling time. Stripping conditions, same as Figure 5a. (c) On-body real time $\mathrm{Cu}$ analysis using a Au based microsensor at different cycling time. Stripping conditions, same as Figure 5c. (d) Calibrated sweat $\mathrm{Cu}$ and $\mathrm{Zn}$ levels measured real-time using a microsensor array during the exercise and measured off-body using ICP-MS from collected samples.

signals to ensure accurate and reliable measurements. The microsensor array has been successfully used to accurately and selectively monitor heavy metal levels in human body fluids such as sweat and urine. Our device greatly expands the panel of analytes for noninvasive wearable biosensing. It could potentially be used to monitor heavy metal exposure and aid in related clinical investigations. Future work involves the full system integration of the flexible sensor array and the wearable circuit board for real-time data processing and transmission. Such a sensing platform is expected to significantly advance the field of wearable biosensors and to promote interdisciplinary collaborations toward realizing personalized medicine.

\section{EXPERIMENTAL SECTION}

Materials. Moisture-resistant polyethylene terephthalate (PET), $100 \mu \mathrm{m}$ thick, was purchased from McMASTER-CARR (Los Angeles, CA). Zinc, cadmium, lead, copper, and mercury standard AAS solutions $(1000 \mathrm{mg} / \mathrm{L}$ in nitric acid), acetate buffer, sodium chloride $(\mathrm{NaCl})$, and Nafion 117 solution (5 wt \%) were purchased from Sigma-Aldrich (St. Louis, MO). All reagents were used as received.

Fabrication of Electrode Arrays. The fabrication process of the electrode arrays is illustrated in Figure 2. Briefly, the sensor arrays on PET were patterned by photolithography using positive photoresist (Shipley Microposit S1818) followed by 30/100 nm Cr/Au deposited via electron beam (e-beam) evaporation and lift-off in acetone. A 500 $\mathrm{nm}$ parylene $\mathrm{C}$ insulation layer was then deposited in a SCS Labcoter 2 Parylene Deposition System. Subsequently, photolithography was used to define the electrode area $(100 \mu \mathrm{m} \times 1200 \mu \mathrm{m})$ followed by $\mathrm{O}_{2}$ plasma etching for $450 \mathrm{~s}$ at $300 \mathrm{~W}$ to completely remove parylene at the defined electrode areas. E-beam evaporation was then performed to pattern $180 \mathrm{~nm} \mathrm{Ag}$ on the electrode areas followed by lift-off in acetone. Finally, photolithography and e-beam evaporation were used to pattern $300 \mathrm{~nm} \mathrm{Bi}$ on the electrode areas followed by lift-off in acetone. One microliter of Nafion 117 solution was then drop casted onto the microsensor array and dried for $2 \mathrm{~h}$. A polydimethylsiloxane (PDMS) well (6 mm diameter and $1 \mathrm{~mm}$ thickness) was fabricated using a soft lithography process. It was bonded to the flexible PET substrate using $\mathrm{O}_{2}$ plasma etching treatment on the PDMS surface for $90 \mathrm{~s}$ at $90 \mathrm{~W}$. The PDMS well allows the accumulation of sufficient sweat volume for stripping analysis. The microelectrodes array was connected to the potentiostat through an interface consisting of a flexible printed circuit connector.

Characterizations of the Microsensor Arrays. Square wave anodic stripping voltammetry (SWASV) was employed to characterize the electrochemical stripping of heavy metals on the microsensor arrays. In order to evaluate the performance of $\mathrm{Bi}$ electrodes, a deposition potential of $-1.5 \mathrm{~V}\left(\mathrm{vs} \mathrm{Ag}^{+} / \mathrm{Ag}\right)$ was applied for $180 \mathrm{~s}$, followed by a SWASV scan to a final potential of $-0.5 \mathrm{~V}\left(\mathrm{vs} \mathrm{Ag}^{+} / \mathrm{Ag}\right.$ ) at a frequency of $60 \mathrm{~Hz}$, an amplitude of $40 \mathrm{mV}$, and a potential step of $4 \mathrm{mV}$ in $0.01 \mathrm{M}$ acetate buffer ( $\mathrm{pH} 4.6$ ) containing $50 \mathrm{mM} \mathrm{NaCl}$. In order to evaluate the performance of Au electrodes, a deposition potential of $-0.7 \mathrm{~V}$ ( $\mathrm{vs} \mathrm{Ag}^{+} / \mathrm{Ag}$ ) was applied for $120 \mathrm{~s}$ (15 s for repeatability tests and detection in biofluids), followed by a SWASV scan to a final potential of $0.8 \mathrm{~V}\left(\mathrm{vs} \mathrm{Ag}^{+} / \mathrm{Ag}\right.$ ) at a frequency of $60 \mathrm{~Hz}$, an amplitude of $40 \mathrm{mV}$, and a potential step of $4 \mathrm{mV}$ in $0.01 \mathrm{M}$ acetate buffer ( $\mathrm{pH}$ 4.6) containing $50 \mathrm{mM} \mathrm{NaCl}$. Mechanical deformation was tested by repeatedly bending (radii of curvature is $3.2 \mathrm{~mm}$ ) the microelectrodes array for 200 times.

Off-Body Calibration and Validation in Human Sweat and Urine. Sweat samples were collected directly from the forehead and the arm of volunteer subjects during their constant load $(150 \mathrm{~W})$ cycling exercise. The subjects' skin was cleaned with alcohol swabs and gauze before the exercise and after every sweat collection. Urine samples were collected from the same volunteer subjects. And $50 \mu \mathrm{L}$ human sweat and urine samples were used for the off-body measurement. The level of heavy metals was estimated by SWASV through standard addition $(1-2 \mu \mathrm{L}$ each time) of $100 \mathrm{mg} / \mathrm{L} \mathrm{Zn}$ or $\mathrm{Cu}$ standard solutions. It should be noted that, in some cases, the peak positions slightly shifted after the standard addition due to the greatly changed heavy metal concentrations. The measurement results of 
biofluid heavy metal levels from the microsensors were compared with the data measured directly through an ICP Optima 7000 DV instrument.

Real Time On-Body Heavy Metal Analysis. On-body evaluation of the microsensor arrays was performed in compliance with the protocol that was approved by the institutional review board at the University of California, Berkeley (CPHS 2014-08-6636). Five healthy subjects (all males), aged 20-40, were recruited from the University of California, Berkeley campus and the neighboring community through advertisement by posted notices, word of mouth, and email distribution. All subjects gave written, informed consent before participation in the study. An electronically braked leg-cycle ergometer (Kettler E3 Upright Ergometer Exercise Bike) was used for cycling trials. The subjects' skin was cleaned with alcohol swabs and gauze before sensors were worn on-body. A constant workload cycling regimen was used in which subjects were cycling at $50 \mathrm{~W}$ with $50 \mathrm{~W}$ increments every $150 \mathrm{~s}$ up to $150 \mathrm{~W}$, and then cycling at $150 \mathrm{~W}$ for 30 min. The 5 min cool down section involved cycling with decreased power output by $50 \mathrm{~W}$ every $150 \mathrm{~s}$. During the exercise, on-body analysis was recorded using a Gamry electrochemical potentiostat (PCI4/G300). The on-body measurement results were calibrated using the measured skin/environment temperature at the same time. Such calibration eliminated the errors of stripping signals resulted from temperature variations. The heavy metal concentrations from on-body tests were roughly estimated using a coefficient factor obtained from an off-body standard addition method shown in Figure S3 (based on the sweat sample collected from previous running test of the same subject). Three sweat samples were also collected in a 5 min period (10-15 $\mathrm{min}, 15-20 \mathrm{~min}, 20-25 \mathrm{~min}$ ) followed by skin cleaning during the same exercise and tested with ICP-MS.

\section{ASSOCIATED CONTENT}

\section{S Supporting Information}

The Supporting Information is available free of charge on the ACS Publications website at DOI: 10.1021/acssensors.6b00287.

Measurement of peak height from a stripping voltammogram, reproducibility of microsensor arrays, and heavy metal analysis in human body fluids (PDF)

\section{AUTHOR INFORMATION}

\section{Corresponding Author}

*E-mail: ajavey@berkeley.edu.

\section{Author Contributions}

"W.G. and H.Y.Y.N. contributed equally to this work.

\section{Notes}

The authors declare no competing financial interest.

\section{ACKNOWLEDGMENTS}

This work was supported by NSF Nanomanufacturing Systems for Mobile Computing and Energy Technologies (NASCENT) Center. The sensor fabrication was performed in the Electronic Materials (E-MAT) laboratory funded by the Director, Office of Science, Office of Basic Energy Sciences, Material Sciences and Engineering Division of the U.S. Department of Energy under Contract No. DE-AC02-05CH11231. K.C. acknowledges support from the Robert N. Noyce Fellowship in Microelectronics. H.O. acknowledges support from the Japan Society for the Promotion of Science (JSPS) Fellowship.

\section{REFERENCES}

(1) Kim, D. H.; Lu, N. S.; Ma, R.; Kim, Y. S.; Kim, R. H.; Wang, S. D.; Wu, J.; Won, S. M.; Tao, H.; Islam, A.; Yu, K. J.; Kim, T. I.; Chowdhury, R.; Ying, M.; Xu, L. Z.; Li, M.; Chung, H. J.; Keum, H.; McCormick, M.; Liu, P.; Zhang, Y. W.; Omenetto, F. G.; Huang, Y. G.;
Coleman, T.; Rogers, J. A. Epidermal Electronics. Science 2011, 333, 838-843.

(2) Bandodkar, A. J.; Wang, J. Non-invasive Wearable Electrochemical Sensors: A Review. Trends Biotechnol. 2014, 32, 363-371.

(3) Schwartz, G.; Tee, B. C. K.; Mei, J.; Appleton, A. L.; Kim, D. H.; Wang, H.; Bao, Z. Flexible Polymer Transistors with High Pressure Sensitivity for Application in Electronic Skin and Health Monitoring. Nat. Commun. 2013, 4, 1859.

(4) Kaltenbrunner, M.; Sekitani, T.; Reeder, J.; Yokota, T.; Kuribara, K.; Tokuhara, T.; Drack, M.; Schwodiauer, R.; Graz, I.; Bauer Gogonea, S.; Bauer, S.; Someya, T. An Ultra-Lightweight Design for Imperceptible Plastic Electronics. Nature 2013, 499, 458-463.

(5) Takei, K.; Takahashi, T.; Ho, J. C.; Ko, H.; Gillies, A. G.; Leu, P. W.; Fearing, R. S.; Javey, A. Nanowire Active-Matrix Circuitry for LowVoltage Macroscale Artificial Skin. Nat. Mater. 2010, 9, 821-826.

(6) Hammock, M. L.; Chortos, A.; Tee, B. C. K.; Tok, J. B. H.; Bao, Z. The Evolution of Electronic Skin (e-skin): A Brief History, Design Considerations, and Recent Progress. Adv. Mater. 2013, 25, 59976037.

(7) Wang, C.; Hwang, D.; Yu, Z.; Takei, K.; Park, J.; Chen, T.; Ma, B.; Javey, A. User-Interactive Electronic Skin for Instantaneous Pressure Visualization. Nat. Mater. 2013, 12, 899-904.

(8) Xu, S.; Zhang, Y.; Jia, L.; Mathewson, K. E.; Jang, K.; Kim, J.; Fu, H.; Huang, X.; Chava, P.; Wang, R.; Bhole, S.; Wang, L.; Na, Y. J.; Guan, Y.; Flavin, M.; Han, Z.; Huang, Y.; Rogers, J. A. Soft Microfluidic Assemblies of Sensors, Circuits, and Radios for the Skin. Science 2014, 344, 70-74.

(9) Takei, K.; Honda, W.; Harada, S.; Arie, T.; Akita, S. Flexible and Wearable Human-Interactive Health-Monitoring Devices. Adv. Healthcare Mater. 2015, 4, 487-500.

(10) Fan, F. R.; Lin, L.; Zhu, G.; Wu, W. Z.; Zhang, R.; Wang, Z. L. Transparent Triboelectric Nanogenerators and Self-Powered Pressure Sensors Based on Micropatterned Plastic Films. Nano Lett. 2012, 12, 3109-3114.

(11) Chen, K.; Gao, W.; Emaminejad, S.; Kiriya, D.; Ota, H.; Nyein, H. Y. Y.; Takei, K.; Javey, A. Printed Carbon Nanotube Electronics and Sensor Systems. Adv. Mater. 2016, DOI: 10.1002/adma.201504958.

(12) Ota, H.; Emaminejad, S.; Gao, Y.; Zhao, A.; Wu, E.; Challa, S.; Chen, K.; Fahad, H. M.; Jha, A. K.; Kiriya, D.; Gao, W.; Shiraki, H.; Morioka, K.; Ferguson, A. R.; Healy, K. E.; Davis, R. W.; Javey, A. Application of 3D Printing for Smart Objects with Embedded Electronic Sensors and Systems. Adv. Mater. Technol. 2016, 1, 1600013.

(13) Schazmann, B.; Morris, D.; Slater, C.; Beirne, S.; Fay, C.; Reuveny, R.; Moyna, N.; Diamond, D. A Wearable Electrochemical Sensor for the Real-Time Measurement of Sweat Sodium Concentration. Anal. Methods 2010, 2, 342-348.

(14) Jia, W.; Bandodkar, A. J.; Valdés-Ramírez, G.; Windmiller, J. R.; Yang, Z.; Ramírez, J.; Chan, G.; Wang, J. Electrochemical Tattoo Biosensors for Real-Time Noninvasive Lactate Monitoring in Human Perspiration. Anal. Chem. 2013, 85, 6553-6560.

(15) Bandodkar, A. J.; Molinnus, D.; Mirza, O.; Guinovart, T.; Windmiller, J. R.; Valdes-Ramirez, G.; Andrade, F. J.; Schoning, M. J.; Wang, J. Epidermal Tattoo Potentiometric Sodium Sensors with Wireless Signal Transduction for Continuous Non-Invasive Sweat Monitoring. Biosens. Bioelectron. 2014, 54, 603-609.

(16) Sonner, Z.; Wilder, E.; Heikenfeld, J.; Kasting, G.; Beyette, F.; Swaile, D.; Sherman, F.; Joyce, J.; Hagen, J.; Kelley-Loughnane, N.; Naik, R. The Microfluidics of the Eccrine Sweat Gland, Including Biomarker Partitioning, Transport, and Biosensing Implications. Biomicrofluidics 2015, 9, 031301.

(17) Gonzalo-Ruiz, J.; Mas, R.; de Haro, C.; Cabruja, E.; Camero, R.; Alonso-Lomillo, M. A.; Muñoz, F. J. Integration of Biosensors and Drug Delivery Technologies for Early Detection and Chronic Management of Illness. Biosens. Bioelectron. 2009, 24, 1788-1791.

(18) Huang, X.; Liu, Y. H.; Chen, K. L.; Shin, W. J.; Lu, C. J.; Kong, G. W.; Patnaik, D.; Lee, S. H.; Cortes, J. F.; Rogers, J. A. Stretchable, Wireless Sensors and Functional Substrates for Epidermal Characterization of Sweat. Small 2014, 10, 3083-3090. 
(19) Kim, J.; Imani, S.; de Araujo, W. R.; Warchall, J.; ValdésRamírez, G.; Paixão, T. R. L. C.; Mercier, P.; Wang, J. Wearable Salivary Uric Acid Mouthguard Biosensor with Integrated Wireless Electronics. Biosens. Bioelectron. 2015, 74, 1061-1068.

(20) Yao, H.; Shum, A. J.; Cowan, M.; Lahdesmaki, I.; Parviz, B. A. A Contact Lens with Embedded Sensor for Monitoring Tear Glucose Level. Biosens. Bioelectron. 2011, 26, 3290-3296.

(21) Chu, M. X.; Kudo, H.; Shirai, T.; Miyajima, K.; Saito, H.; Morimoto, N.; Yano, K.; Iwasaki, Y.; Akiyoshi, K.; Mitsubayashi, K. A Soft and Flexible Biosensor Using a Phospholipid Polymer for Continuous Glucose Monitoring. Biomed. Microdevices 2009, 11, 837842.

(22) Bandodkar, A. J.; Jia, W.; Yardımcı, C.; Wang, X.; Ramirez, J.; Wang, J. Tattoo-Based Noninvasive Glucose Monitoring: A Proof-ofConcept Study. Anal. Chem. 2015, 87, 394-398.

(23) Gao, W.; Emaminejad, S.; Nyein, H. Y. Y.; Challa, S.; Chen, K.; Peck, A.; Fahad, H. M.; Ota, H.; Shiraki, H.; Kiriya, D.; Lien, D.-H.; Brooks, G. A.; Davis, R. W.; Javey, A. Fully Integrated Wearable Sensor Arrays for Multiplexed In Situ Perspiration Analysis. Nature 2016, 529, 509-514.

(24) Lee, H.; Choi, T. K.; Lee, Y. B.; Cho, H. R.; Ghaffari, R.; Wang, L.; Choi, H. J.; Chung, T. D.; Lu, N.; Hyeon, T.; Choi, S. H.; Kim, D. H. A Graphene-Based Electrochemical Device with Thermoresponsive Microneedles for Diabetes Monitoring and Therapy. Nat. Nanotechnol. 2016, DOI: $10.1038 /$ nnano.2016.38

(25) Cohn, J. R.; Emmett, E. A. The Excretion of Trace Metals in Human Sweat. Ann. Clin. Lab Sci. 1978, 8, 270-275.

(26) Sears, M. E.; Kerr, K. J.; Bray, R. I. Arsenic, Cadmium, Lead, and Mercury in Sweat: A Systematic Review. J. Environ. Public Health 2012, 2012, 184745.

(27) Mudgal, V.; Madaan, N.; Mudgal, A.; Singh, R. B.; Mishra, S. Effect of Toxic Metals on Human Health. Open Nutraceuticals J. 2010, 3, 94-99.

(28) Fraga, C. G. Relevance, Essentiality and Toxicity of Trace Elements in Human Health. Mol. Aspects Med. 2005, 26, 235.

(29) Schaefer, M.; Schellenberg, M.; Merle, U.; Weiss, K. H.; Stremmel, W. Wilson Protein Expression, Copper Excretion and Sweat Production in Sweat Glands of Wilson Disease Patients and Controls. BMC Gastroenterol. 2008, 8, 29.

(30) Hohnadel, D. C.; Sunderman, F. W., Jr.; Nechay, M. W.; McNeely, M. D. Atomic Absorption Spectrometry of Nickel, Copper, Zinc, and Lead in Sweat Collected from Healthy Subjects during Sauna Bathing. Clin. Chem. 1973, 19, 1288-1292.

(31) Munro, S.; Ebdon, L.; McWeeny, D. J. J. Application of Inductively Coupled Plasma Mass Spectrometry (ICP-MS) for Trace Metal Determination in Foods. J. Anal. At. Spectrom. 1986, 1, 211219.

(32) Wang, J. Stripping Analysis: Principles, Instrumentation, and Applications; VCH Publishers: Deerfield Beach, FL, 1985.

(33) Stauber, J. L.; Florence, T. M. The Determination of Trace Metals in Sweat by Anodic Stripping Voltammetry. Sci. Total Environ. 1987, 60, 263-271.

(34) de Souza, A. P. R.; Lima, A. S.; Salles, M. O.; Nascimento, A. N.; Bertotti, M. The Use of a Gold Disc Microelectrode for the Determination of Copper in Human Sweat. Talanta 2010, 83, 167170.

(35) Crew, A.; Cowell, D. C.; Hart, J. P. Development of an Anodic Stripping Voltammetric Assay, Using a Disposable Mercury-Free Screen-Printed Carbon Electrode, for the Determination of Zinc in Human Sweat. Talanta 2008, 75, 1221-1226.

(36) Hutton, E. A.; Ogorevc, B.; Hočevar, S. B.; Smyth, M. R. Bismuth Film Microelectrode for Direct Voltammetric Measurement of Trace Cobalt and Nickel in Some Simulated and Real Body Fluid Samples. Anal. Chim. Acta 2006, 557, 57-63.

(37) Kim, J.; de Araujo, W. R.; Samek, I. A.; Bandodkar, A. J.; Jia, W.; Brunetti, B.; Paixão, T. R.L.C.; Wang, J. Wearable Temporary Tattoo Sensor for Real-Time Trace Metal Monitoring in Human Sweat. Electrochem. Commun. 2015, 51, 41-45.
(38) Wang, J. Stripping Analysis at Bismuth Electrodes: A Review. Electroanalysis 2005, 17, 1341-1346.

(39) Bonfil, Y.; Brand, M.; Kirowa-Eisner, E. Characteristics of Subtractive Anodic Stripping Voltammetry of $\mathrm{Pb}$ and $\mathrm{Cd}$ at Silver and Gold Electrodes. Anal. Chim. Acta 2002, 464, 99-114.

(40) Wang, J.; Deo, R. P.; Thongngamdee, S.; Ogorevc, B. Effect of Surface-Active Compounds on the Stripping Voltammetric Response of Bismuth Film Electrodes. Electroanalysis 2001, 13, 1153-1156.

(41) Pei, X.; Kang, W.; Yue, W.; Bange, A.; Heineman, W. R.; Papautsky, I. Disposable Copper-Based Electrochemical Sensor for Anodic Stripping Voltammetry. Anal. Chem. 2014, 86, 4893-4900.

(42) Soleymani, L.; Fang, Z.; Lam, B.; Xiaomin Bin, X.; Vasilyeva, E.; Ross, A. J.; Sargent, E. H.; Kelley, S. O. Hierarchical Nanotextured Microelectrodes Overcome the Molecular Transport Barrier to Achieve Rapid, Direct Bacterial Detection. ACS Nano 2011, 5, $3360-3366$

(43) Omokhodion, F. O.; Howard, J. M. Lead in Sweat and its Relationship to Salivary and Urinary Levels in Normal Healthy Subjects. Sci. Total Environ. 1991, 103, 123-128. 